\title{
Specific Cutting Conditions of 100Cr6 Steel Grinding and Selected Final Roughness Parameters
}

\author{
Nataša Náprstkovái ${ }^{*}$, Martin Novák ${ }^{1}$, Jan Sviantek ${ }^{1}$ \\ ${ }^{1}$ Jan Evangelista Purkyně University in Ústí nad Labem, Faculty of Mechanical Engineering, Pasteurova 7, \\ 40096 Ústí nad Labem, Czech Republic \\ * Corresponding author’s e-mail: natasa.naprstkova@ujep.cz
}

\begin{abstract}
Grinding of hardened steels is often an important used technology at finishing. Products made from these materials in mechanical engineering are often used, and a quality of the workpiece surface roughness after grinding is one of the important parameters that to us speaks about the quality of the machining process. The paper deals with the influence of the selected cutting conditions when grinding bearing steel 100Cr6 (EN 10027-1) on their machined surface roughness.
\end{abstract}

Keywords: hardened steel, final surface, roughness, grinding

\section{INTRODUCTION}

This article deals with an experiment that was carried out at Faculty of Mechanical Engineering at Jan Evangelista Purkyně Univeristy in Ústí nad Labem (FME JEPU). There is described one of many experiments carried out here on a similar theme. The essence of experiment was the grinding of $100 \mathrm{Cr} 6$ bearing steel under certain cutting conditions, when the obtained surface was subsequently evaluated for view of its roughness $[1,2]$.

The steel 100Cr6 (in according of standard EN 10027-1) is most used for the production of rolling bearings, more precisely for the production of rings and rolling elements of these bearings. With regard to its use, this steel is subject to high fatigue and wear resistance. In terms of its structure, it is chromium steel with a predominant amount of granular perlite in the structure. It is suitable for quenching and is not prone to overheating. It is suitable for the production of balls up to $0.25 \mathrm{~mm}$ in diameter, rollers and cones up to $0.18 \mathrm{~mm}$ in diameter and roller bearing rings up to $16 \mathrm{~mm}$ in thickness. But this material is otherwise used across the entire range of engineering products and components. The steel is very good for hro forming using and is suitable for direct quenching, it is well machined in soft annealed condition, too. It is suitable for components with a very hard, wear-resistant surface. Semi-finished products of this steel can be supplied in the form of billets, hot-rolled bars, forgings, seamless hot-formed tubes, cold-drawn bars and cold-drawn wires. The yield strength Re has a value of $441 \mathrm{MPa}$ and the breaking strength $\mathrm{Rm}$ to $765 \mathrm{MPa}$ according to the suppliers. The yield strength Re has a value of $441 \mathrm{MPa}$ and the breaking strength $\mathrm{Rm}$ to $765 \mathrm{MPa}$ according to the suppliers $[3,4,5,6]$.

The samples were grinding. Grinding technology belongs with the honing, lapping and superfinishing to abrasive finishing methods. In terms of the technological parameters of finishing technologies are particularly important the parameters of the achieved precision machined surfaces $[7,8,9]$.

On the samples the surface roughness was measured. The surface roughness is a parameter describing the qualitative character of the machined surface and it is one of the many parameters that must take technologist into account when choosing a machine tool and the used cutting 
tool and when determining cutting conditions. In the actual design and construction the designer should be used when prescribing to choose lower roughness values only in areas where it is from the perspective of technological design and use appropriate, in order to avoid becoming more expensive production components. Quality of surfaces are usually done by grinding $[1,3,8]$.

\section{EXPERIMENT}

In the Table 1 . the chemical composition of the experimental material according to the material standard $100 \mathrm{Cr} 6$ steel is summarized and in the Table 2. the chemical composition of experimental material found by spectral analysis, which was realized at FME JEPU $[3,4,5]$.

The experimental material was ground under selected cutting conditions and the surface roughness was subsequently evaluated for certain of its parameters. Grinding is generally used for finishing surfaces $[2,10,11,12]$.

In the frame of experiment, befor grinding the steel was quenched and tempered to $62 \mathrm{HRC}$. The quenching temperature was $835^{\circ} \mathrm{C}$ with a 15 minute delay and subsequent cooling into water. This was followed by tempering at $170{ }^{\circ} \mathrm{C}$ and a delay of 40 minutes with cooling in air.

The grinding of experimental samples was carried out on the center grinder BU-16. This grinding machine is available for this purpose in FME laboratories. Surface machining was performed by grooving (plunge grinding), see Figure 1.

A microcrystalline corundum wheel with the designation AG 92/99 $150 \mathrm{~K} 8 \mathrm{~V}$ was used for grinding. This type of grain has a high material removal capacity and low need for dressing. Therefore, this grain is suitable for hard materials grinding. In terms of hardness, it is a soft disc with very fine grain, with medium porosity, which is bonded by a ceramic binder $[1,2]$.

SEMIX Al $5000 \mathrm{CZ}$ process liquid (5\% aqueous solution) was used for machining, which is suitable for all kinds of grinding, but also for turning, milling, etc. This liquid is widely used for the material to be machined, since it can be used e.g. for steels, cast irons, copper alloys and zinc alloys $[1,2]$.

Cutting conditions of experiment are in Table 3. Two sets of samples were grinded and identified as A1 to A7 and B1 to B7.

\section{Measurement of grinded samples roughness}

The surface roughness parameters of the resulting surface were measured using the Hommel tester T1000 in accordance with the standard EN ISO 4287. On the Figure 2 is presentation of the sample measuring.

Roughness parameters Ra, Rz, Rt and Rmax, which were obtained on the basis of measuring protocols, were used for evaluation of experiments. These values have been selected for evaluation because they are values that are often used in practice to describe and evaluate the resulting surfaces (eg in the automotive industry) [11, 12, 13].

Twelve measurements were made on each sample at various locations around its perimeter. The recorded track of the sensor was $4.8 \mathrm{~mm}$ and the measurement range was set to $80 \mu \mathrm{m}$. Averages were determined for individual samples and the standard deviation $\sigma$ was calculated $[14,15]$.

\section{Evaluation of measurement results}

The first parameter evaluated was Ra (average arithmetic deviation of roughness profile). Figure 3. shows the values of this parameter at $v_{f r}=0.13 \mathrm{~mm} \cdot \mathrm{min}^{-1}$ and $0.17 \mathrm{~mm} \cdot \mathrm{min}^{-1}$. It is

Table 1. Chemical composition of $100 \mathrm{Cr} 6$ steel according to material sheet (standard EN ISO) [wt. \%]

\begin{tabular}{|c|c|c|c|c|c|c|c|}
\hline \multirow{2}{*}{ Material } & C & $\mathrm{Si}$ & $\mathrm{Mn}$ & P & S & $\mathrm{Cr}$ & \multirow{2}{*}{$\begin{array}{c}\text { Hardness } \\
\text { [HRC] }\end{array}$} \\
\hline & \multicolumn{6}{|c|}{ [wt. \%] } & \\
\hline $\begin{array}{c}100 \mathrm{Cr} 6 \\
(1.2067)\end{array}$ & $0.95-1.10$ & $0.15-0.35$ & $0.25-0.45$ & $\max .0 .03$ & $\max .0 .03$ & $1.35-1.65$ & 64 \\
\hline
\end{tabular}

Table 2. Chemical composition of $100 \mathrm{Cr} 6$ steel according to spectral analysis [wt. \%]

\begin{tabular}{|c|c|c|c|c|c|c|c|c|}
\hline \multirow{2}{*}{ Material } & C & $\mathrm{Si}$ & $\mathrm{Mn}$ & $P$ & $S$ & $\mathrm{Cr}$ & $\mathrm{Cu}$ & \multirow{2}{*}{$\begin{array}{c}\text { Hardness } \\
\text { [HRC] }\end{array}$} \\
\hline & \multicolumn{7}{|c|}{ [wt. \%] } & \\
\hline $\begin{array}{c}100 \mathrm{Cr} 6 \\
(1.2067)\end{array}$ & 0.9 & 0.15 & 0.3 & 1 & I & 1.3 & 0.25 & 62 \\
\hline
\end{tabular}




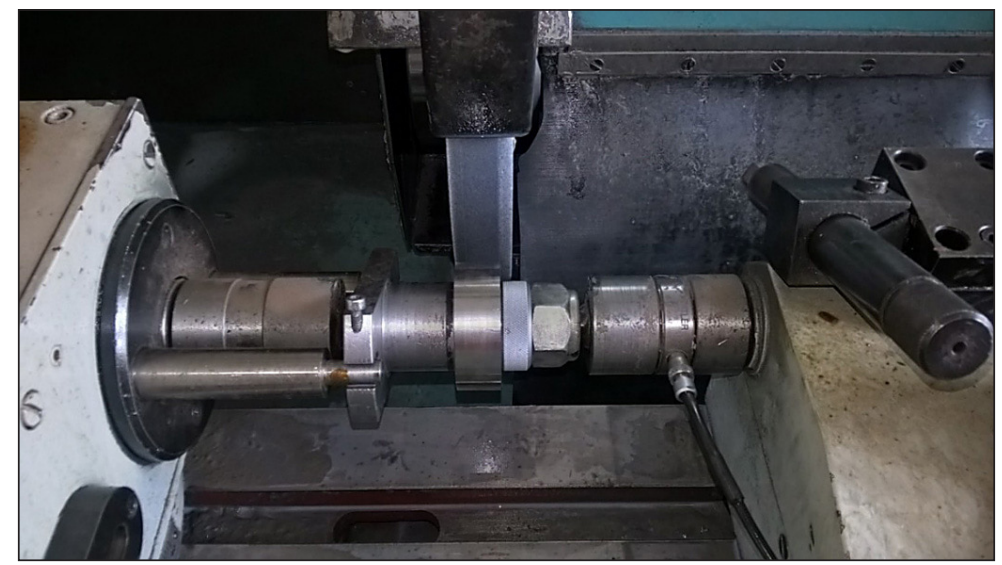

Fig. 1. Grinding of experimental sample

apparent for $v_{f r}=0.17 \mathrm{~mm} \cdot \mathrm{min}^{-1}$ that the speed effect $v_{c}$ on this parameter was not significant, even though it was visible. The lowest Ra value was obtained at the highest speed $v_{c}=43 \mathrm{~m} \cdot \mathrm{s}^{-1}$, namely $\mathrm{Ra}=0.519 \mu \mathrm{m}$. The second best value of Ra was obtained for $v_{c}=41 \mathrm{~m} \cdot \mathrm{s}^{-1}$. For $v_{f r}=$ $0.13 \mathrm{~mm} \cdot \mathrm{min}^{-1}$ the lowest value of Ra parameter at a speed $v_{c}=37 \mathrm{~m} \cdot \mathrm{s}^{-1}$ was achieved, it was Ra $=0.191 \mu \mathrm{m}$. The second lowest value Ra parameter for the $v_{c}=39 \mathrm{~m} \cdot \mathrm{s}^{-1}$ was achieved. Parameter $\mathrm{Ra}$ for the cutting speeds in the range from 35 to $43 \mathrm{~m} \cdot \mathrm{s}^{-1}$ was in the nearby values, and between of these values was not great differences. When comparing for both $v_{f r}$, it can be stated that there is an increase in the value of this parameter for $v_{f r}=0.17 \mathrm{~mm} \cdot \mathrm{min}^{-1}$. Especially at speeds $v_{c}=35$ to $43 \mathrm{~m} \cdot \mathrm{s}^{-1}$ this is more than double the increase.

Furthermore, the parameter $\mathrm{Rz}$ (the highest profile height) was evaluated. Figure 4 shows this parameter again at $v_{f r}=0.13 \mathrm{~mm} \cdot \mathrm{min}^{-1}$ and

Table 3. Cutting conditions of experiments

\begin{tabular}{|c|c|c|}
\hline Sample & $\begin{array}{c}\text { Cutting speed } v_{c} \\
{[\mathrm{~m} / \mathrm{s}]}\end{array}$ & Infeed $v_{f r}[\mathrm{~mm} / \mathrm{min}]$ \\
\hline A1 & 31 & \\
\hline A2 & 33 & \\
\hline A3 & 35 & \multirow{2}{*}{0.13} \\
\hline A4 & 37 & \\
\hline A5 & 39 & \\
\hline A6 & 41 & \\
\hline A7 & 43 & \\
\hline B1 & 31 & \\
\hline B2 & 33 & \multirow{2}{*}{0.17} \\
\hline B3 & 35 & \\
\hline B4 & 37 & \\
\hline B5 & 39 & \\
\hline B6 & 41 & \\
\hline B7 & 43 \\
\hline
\end{tabular}

$0.17 \mathrm{~mm} \cdot \mathrm{min}^{-1}$. For $v_{f r}=0.13 \mathrm{~mm} \cdot \mathrm{min}^{-1}$ the best value for the speed $v_{c}=39 \mathrm{~m} \cdot \mathrm{s}^{-1}$ was achieved, it corresponds with $\mathrm{Rz}=1.569 \mu \mathrm{m}$. The second lowest value of Rz parameter for $v_{c}=37 \mathrm{~m} \cdot \mathrm{s}^{-1}$ was achieved. For $v_{f r}=0.17 \mathrm{~mm} \cdot \mathrm{min}^{-1}$ it can be stated that the influence of speed $v_{c}$ on this parameter was also not so significant, even though it was visible. Again, only a slight change in cutting speed is visible. The best value was achieved for speed $v_{c}=43 \mathrm{~m} \cdot \mathrm{s}^{-1}$, specifically $\mathrm{Rz}=3.806 \mu \mathrm{m}$. The second best $\mathrm{Rz}$ value was obtained for $v_{c}=$ $39 \mathrm{~m} \cdot \mathrm{s}^{-1}$. The course of the obtained values is therefore slightly different than for the Ra parameter, although here too we can speak of a decreasing tendency of the $\mathrm{Rz}$ parameter towards the increasing speed $v_{c}$. When comparing both $v_{f r}$, it can be stated, that there is a significant increase in Rz for $v_{f r}=0.17 \mathrm{~mm} \cdot \mathrm{min}^{-1}$, similar to Ra. The greatest increase is seen at cutting speeds $v_{c}$ from 35 to $43 \mathrm{~m} \cdot \mathrm{s}^{-1}$.

Furthermore, the parameter Rt (total profile height) was evaluated, see Figure 5. The results are again similar as for the parameters $\mathrm{Ra}$ and $\mathrm{Rz}$, and it was possible to say for the previous measured parameters, the cutting speed has a noticeable influence on this parameter. The lowest value of Rt parameter for $v_{f r}=0.13 \mathrm{~mm} \cdot \mathrm{min}^{-1}$ by cutting speed $v_{c}=39 \mathrm{~m} \cdot \mathrm{s}^{-1}$ was achieved, as for $\mathrm{Rz}$ parameter, it was $\mathrm{Rt}=1.886 \mu \mathrm{m}$. The second lowest value of Rt parameter for $v_{c}=43 \mathrm{~m} \cdot \mathrm{s}^{-1}$ was achieved. For $v_{f r}=0.17 \mathrm{~mm} \cdot \mathrm{min}^{-1}$, the course of Rt was also similar as parameter Rz. Again, as for $\mathrm{Rz}$, the lowest (best) value was obtained at the $v_{c}=39 \mathrm{~m} \cdot \mathrm{s}^{-1}$, namely $\mathrm{Rt}=4.826 \mu \mathrm{m}$. The second best Rt value was obtained for $v_{c}=41 \mathrm{~m} \cdot \mathrm{s}^{-1}$, when $\mathrm{Rt}=5,094 \mu \mathrm{m}$. It can also be stated here that the difference between the individual Rt values, as in previous cases, is insignificant, albeit 


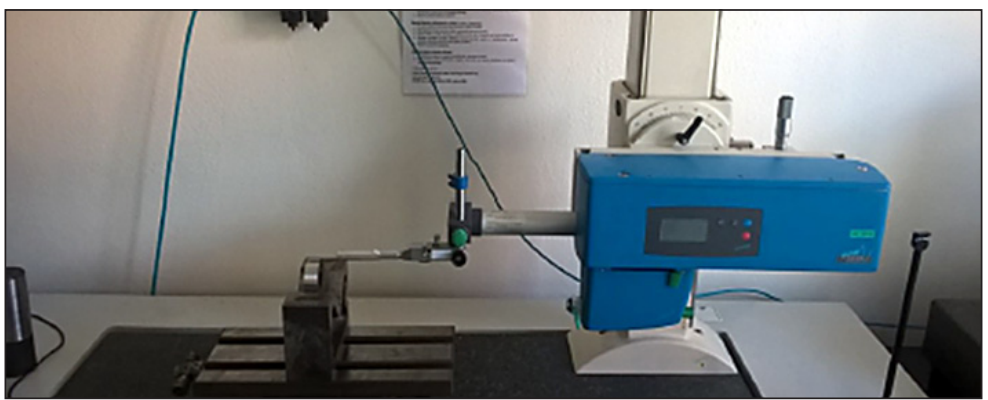

Fig. 2. Measuring of sample at device Hommel tester T1000

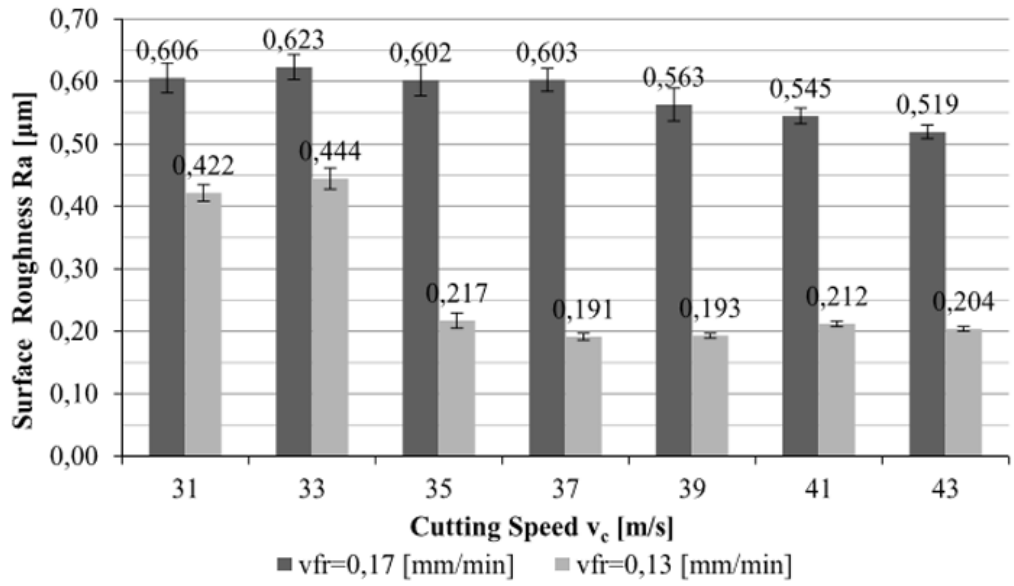

Fig. 3. The values of average roughness for Ra parameter

observable. When comparing $v_{f r}=0.13 \mathrm{~mm} \cdot \mathrm{min}^{-1}$ and $0.17 \mathrm{~mm} \cdot \mathrm{min}^{-1}$, again, as with the abovementioned roughness parameters, we can see a significant deterioration of the Rt parameter for higher $v_{f r}$.

Another evaluated parameter was the parameter Rmax (maximum profile depth), as well as the parameters $\mathrm{Ra}, \mathrm{Rz}$, and $\mathrm{Rt}$, as here, the trend was similar (Fig. 6). Even there is a clear impact of the cutting speed changes on the parameter Rmax. The lowest value for $v_{f r}=0.13 \mathrm{~mm} \cdot \mathrm{min}^{-1}$ again at the speed $v_{c}=39 \mathrm{~m} \cdot \mathrm{s}^{-1}$ was achieved, when $\mathrm{Rmax}=1.814 \mu \mathrm{m}$. And as for Rt and Rz, there was also achieved the second lowest Rmax for $v_{c}=37 \mathrm{~m} \cdot \mathrm{s}^{-1}$.

For $v_{f r}=0.17 \mathrm{~mm} \cdot \mathrm{min}^{-1}$ it was true that there was visible again a similar trend here as for the parameters Rz and Rt. Again, the lowest value was achieved when grinding with the $v_{c}=39 \mathrm{~m} \cdot \mathrm{s}^{-1}$, where the Rmax value was $4.488 \mu \mathrm{m}$. The second best parameter Rmax was obtained for $v_{c}=$ $41 \mathrm{~m} \cdot \mathrm{s}^{-1}$. As with other roughness parameters,

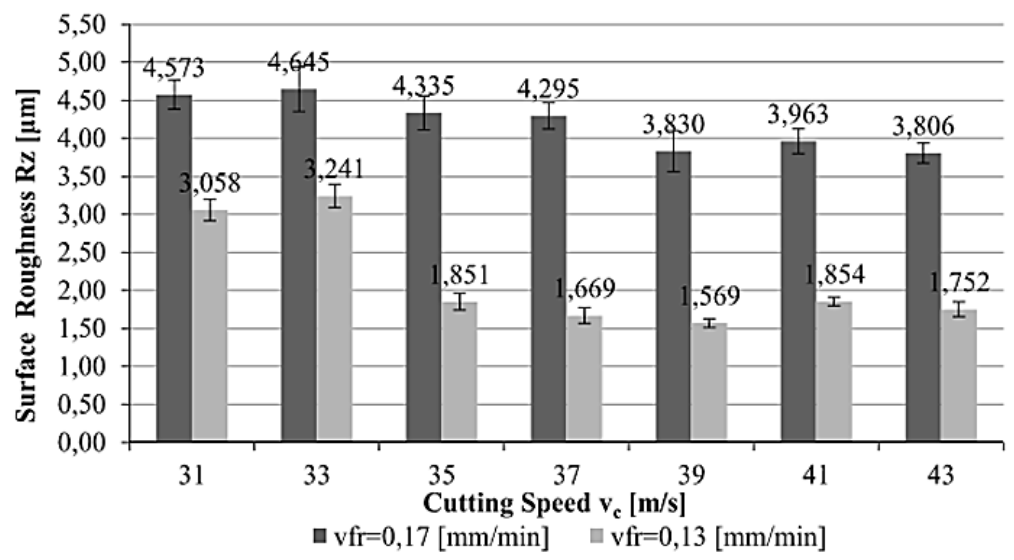

Fig. 4. The values of average roughness for Rz parameter 


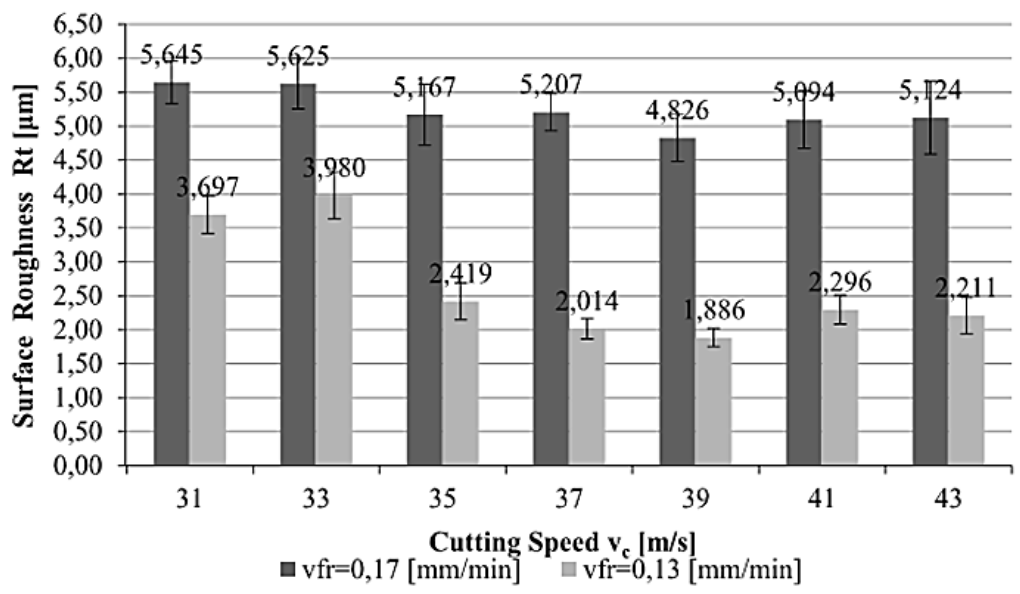

Fig. 5. The values of average roughness for Rt parameter

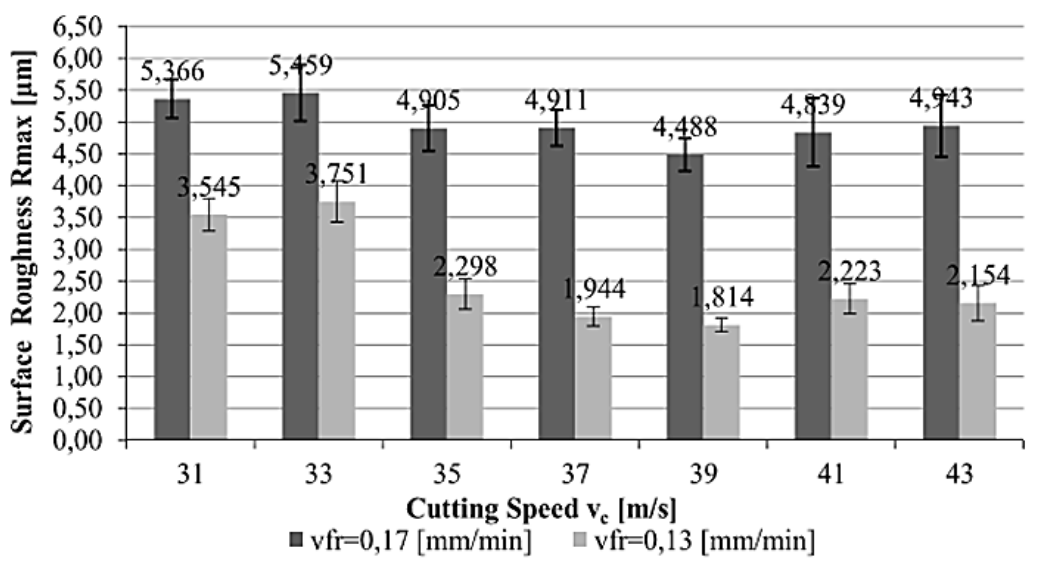

Fig. 6. The values of average roughness for Rmax parameter

a better parameter for $v_{f r}=0.13 \mathrm{~mm} \cdot \mathrm{min}^{-1}$ was achieved here as well.

From realized measuring was visible the effect of changes in radial infeed velocity $v_{f i}$. The trends in graphs show an increase in all parameters at given cutting speeds. At certain cutting speeds, these parameters are more than doubled.

All these findings lead to the conclusion that when grinding the material $10 \mathrm{Cr} 6$ with a disc type AG $92 / 99150 \mathrm{~K} 8 \mathrm{~V}$ it is preferable to use the infeed $v_{f r}=0.13 \mathrm{~mm} \cdot \mathrm{min}^{-1}$ and thus guarantee the creation of a better surface in terms of roughness parameters.

\section{CONCLUSIONS}

From realized measurin the effect of changes in radial infeed velocity $v_{f r}$ was visible. Measured values of individual roughness parameters showed an increase (deterioration) in all evaluated profile parameters at $v_{f r}=0.17 \mathrm{~mm} \cdot \mathrm{min}^{-1}$. At some cutting speeds $v_{c}$, these parameters were even more than doubled. This deterioration of the machined surface is probably attributable to the fact that increasing the radial infeed rate $v_{f r}$ acts on the primary plastic deformation area. Increasing $v_{f r}$ according to this assumption acts by increasing the area of primary plastic deformation and turning it towards the material being machined. This fact affects the surface created negatively. Based on the measured values, it is therefore possible to unambiguously recommend the use of a lower radial infeed velocity $v_{f r}=0.13 \mathrm{~mm} \cdot \mathrm{min}^{-1}$ for the given material. It is then possible to recommend $v_{c}=$ $39 \mathrm{~m} \cdot \mathrm{s}^{-1}$. At this speed, the best profile (roughness) parameters were achieved.

The presented experiment is part of more extensive research carried out at FME JEPU.

\section{Acknowledgement}

The article was suported by projects No. CZ.1.05/4.1.00/11.0260 EDIMARE, SGS UJEP 2019 and UJEP-IGA-TC-2019-48-01-2. 


\section{REFERENCES}

1. Novak M., Surface Quality of Hardened Steels after Grinding. Manufacturing Technology 10(11), 2011, 55-59.

2. Novak M., Surfaces with High Precision of Roughness after Grinding. Manufacturing Technology 12(13), 2012, 66-70.

3. ČSN EN ISO 683-17, Heat-treated steels, alloy steels and free-cutting steels - Part 17: Ball and roller bearing steels, 2002.

4. ČSN EN 10027-1, Designation systems for steels. Part 1: Steel names, 2006.

5. ČSN EN 10027-2, Designation systems for steels. Part 2: Numerical system, 1995.

6. Chakraborty J., D. Bhattacharjee, I. Manna, Austepering of Bearing Steel for Improved Mechanical Properties. Scripta Materialia 59, 2008, 247-250.

7. Byrne P., Turning, Milling and Grinding Processes. Arnold, London, 1996.

8. Marinescu I.D. et al., Handbook of Machining with Grinding Wheels. CRC Press, Boca Raton, 2007.

9. Pitrmuc Z., J. Capek, K. Kolarik, L. Beranek, J. Urban, Tool Geometry Influence on Surface Integrity of Machined Austenite Stainless Steel. Manu- facturing Technology, 16(2), 2016, 425-431.

10. Kundrák J., C. Felho, 3D Roughness Parameters of Surfaces Face Milled by Special Tools. Manufacturing Technology, 16(3), 2016, 532-538.

11. Malotova S., R. Cep, L. Cepova, J. Petru, D. Stancekova, L. Kyncl, M. Hatala, Roughness Evaluation of the Machined Surface at Interrupted Cutting Process. Manufacturing Technology, 16(1), 2014, 168-173.

12. Valíček J., J. Rusnák, M. Müller, P. Hrabě, M. Kadnar, S. Hloch, M. Kušnerová, Geometrické aspekty drsnosti povrchu klasických a netradičních technologií. Jemná mechanika a optika, 53(9), 2008, 249-253.

13. ČSN EN ISO 4287 Geometrical product specifications (GPS) - Surface texture: Profile method - Terms, definitions and surface texture parameters, 1999.

14. Ťavodová M., The Surface Quality of Materials after Cutting by Abrasive Water Jet Evaluated by Selected Methods. Manufacturing technology, 13(2), 2013, 236-241.

15. Osička K., Průměrná aritmetická úchylka drsnosti povrchu - statistické vyhodnocení plochy. Strojírenská technologie, 14(1), 2009, 30-32. 